\title{
Working out an incomplete cyclic train timetable for high-speed railways by computer
}

\author{
D. Yang, L. Nie, Y. Tan, Z. He \& Y. Zhang \\ School of Traffic and Transportation, Beijing Jiaotong University, China
}

\begin{abstract}
Cyclic train timetables as a popular mode of train operation have been successfully applied for many years in European railways, especially in highspeed railways (hereinafter referred to as 'HSR'). However, in China, most studies on the train timetables of HSR still follow the traditional mode. By analyzing the characteristics of Chinese HSR, this paper proposes an incomplete cyclic timetable mode that will be more suitable for the Chinese situation. The characteristics and process of working out incomplete a cyclic train timetable are discussed. There are four key issues involved in developing this kind of timetable: (1) Adaptability analyzing. This paper analyzes the proportion of trains that can be operated cyclically in terms of the technical condition and passenger flow of each HSR in order to determine the structure of the timetable. (2) Model developing. By analyzing the condition of the Chinese HSR, the existing model is improved to solve the problem more precisely and practically. (3) Non-cyclic train path insertion. According to the travel demand of passengers, the principles and technologies of inserting non-cyclic train paths into cyclic train paths is developed. (4) Seasonal expanding. The seasonal fluctuation of passenger flow makes more non-cyclic train paths. The ways to balance the disaccord in different periods are discussed to keep the operation efficient. Furthermore, a system using $\mathrm{VC}++$ is designed with consideration of the four issues in its functions and working process, based on inputting the solution of the model. Finally, a successful case of the Beijing-Shanghai HSR shows the feasibility of the incomplete cyclic timetable and the practical value of the system.
\end{abstract}


Keywords: incomplete cyclic train timetable, Beijing-Shanghai high-speed railway, computer system.

\section{Introduction}

HSR has become a world tendency. As a key work of the HSR organization and management, how to work out a reasonable and scientific train timetable is an important subject to experts and scholars. The cyclic train timetable is an advanced mode of train operation that has been successfully applied for many years in the world.

Scholars have adopted a variety of mathematical methods to solve cyclic timetable problems gradually with the introduction of train timetables worked out by computer. In 1980, Assad [1] first utilized a mathematical model to work out a solution to a transport problem. Subsequently, many experts began to utilize mathematical model to research train timetables and designed a series of numerations. Serafini and Ukovich [2] promoted the Period Event Scheduling Problem (PESP) in 1989, which is very similar to the cyclic railway timetable problem. Currently, most scholars tend to research modes and algorithms based on PESP. In 1996, Odijk [3] utilized PESP design numeration to work out a series of train timetables and compared the similarities and differences of the train timetable to supply a detailed illustration of the expansion scheme of stations. In 2002, Giesemann [4] utilized numeration to establish a simple mathematical model and get a train timetable suitable for a small station. In 1996, Nachtigall and Voget [5] worked out a train timetable with passengers' minimum latency as the objective. In 2000, based on Serafini and Ukovich's idea, Linder [6] introduced the branch and bound method into train timetable design and rolling stock turnover programming, with the objective of a minimum train fleet. Graph theory knowledge is used by literature [7] to connect circles of a constrain graph and train timetable with the change train timetable problem to a mixed integer programming problem. The results of other studies, [8,9], showed some methods to control the traffic. In recent years, Chinese researchers have done a great many of researches on the train timetable of HSR: the cyclic timetable has been suggested to be applied in China's HSR [10,11], and a model and algorithm of working out the cyclic timetable have been discussed [12-14]; in addition, computers are also being applied to draw train timetables [15].

Generally speaking, scholars has made some research on working out the HSR cyclic timetable and have achieved some results; however, most of the researches is mainly on the complete cyclic mode and has not taken the combination of cycle and non-cycle into consideration. Moreover, the research on how to utilize a computer to work out the incomplete cyclic mode is comparatively rare. Although China has many HSR, which are long and wide spread, train timetables still follow the traditional mode. So a suitable timetable mode and methods of working out timetables need to be developed. This paper researches four key problems that shall be solved in its working out method and working out course, and then proposes an incomplete cyclic timetable mode. 
Meanwhile, the paper also designs and develops a computer system to work out a train timetable of the Beijing-Shanghai high speed railway.

\section{Incomplete cyclic timetable mode}

Theoretically, a cyclic timetable means train paths are repeated in each cycle $\mathrm{T}$ (e.g. 1 hour) in a basic train timetable, that is to say the departure/arrival time, the departure/arrival sequences and the dwell time of trains are the same in every cycle.

\subsection{Introduction to the incomplete cyclic timetable}

China has a large high speed railway network, and too many passenger flow ODs with a complex passenger flow structure. The timetable structure has its own features as follows:

(1) Only partial railway lines have the condition to adopt the cyclic timetable, other railway lines can only adopt the timetable with the combination mode of cyclic and non-cyclic, because long lines can be affected easily by night trains and over-line trains with different OD.

(2) The mixed operation of high speed and medium speed lines adopt the model based on PESP to solve the timetable structure, but it is difficult to guarantee the robustness of the timetable as there is too much overtaking and waiting time.

(3) No solution or low quality solution appears easily when the PESP-based model is adopted for lines with long distance and heavy density passenger flow, as there are many variables of the model, and it brings increasing difficulties in solving the model.

Considering the above situation, the complete cyclic timetable and current model cannot fully meet the demand of China's situation. This paper puts forward a modified timetable mode, named the incomplete cyclic timetable mode, in order to suit the Chinese HSR, which means that the complete cyclic timetable is recommended for lines that are characterized by short or mediumlong distance, high train frequency and large passenger flow. For those long distance lines, only partial sections with enough passenger flow can adopt the cyclic mode timetable. In other situations, the combination mode of the cyclic and non-cyclic timetable should be adopted. To work out an incomplete timetable, some non-cyclic paths have to be added into the cyclic timetable.

\subsection{Flowchart of incomplete cyclic timetable design}

Drawing a timetable is a difficult task, which needs to use some mathematical method and computer programming. The process of working out an incomplete cyclic timetable is shown in Figure 1.

Figure 1 shows that an incomplete cyclic timetable takes the cyclic train service plan as a precondition. Firstly, a peak hour timetable needs to be designed through solving a mathematical model, and then expanded to a 24-hour timetable on the basis of passenger flow. In practice, train paths are removed and 
train paths are inserted, considering different passenger is demanded in each hour, and index statistics are necessary in order to feed back useful information on the timetable, so it can help the operator to find the problem in a timely manner and solve it quickly. Moreover, adding or removing non-cyclic train paths properly helps to expand the timetable to a weekly timetable and a seasonal timetable according to actual passenger flow changes.

\subsection{Key issues for an incomplete cyclic train timetable}

There are four key issues for working out a cyclic train timetable by mathematical model and computer system.

\subsubsection{Adaptability analysis}

The cyclic timetable is suitable for HSR with high train frequency. If the running cycle is one hour and excludes six hours overnight, the passenger flow in some sections shall reach at least $18 * 800=14400$ persons everyday to satisfy the running condition of cyclic trains. For the lower passenger flow density, a two hour cycle can be suggested with the addition of some non-cyclic paths.

Six high-speed railway lines have been opened to traffic and their statistics are shown in Table 1.

Table 1 shows that the passenger flow of most of the railway lines has largely exceeded the least passenger flow required by cyclic running trains. Certainly, some sections may not meet the conditions for opening a cyclic timetable. So adopting the methods of train path removal and train path insertion based on cyclic lines to make an adjustment is required. Finally, a timetable in the incomplete cyclic timetable mode is formed.

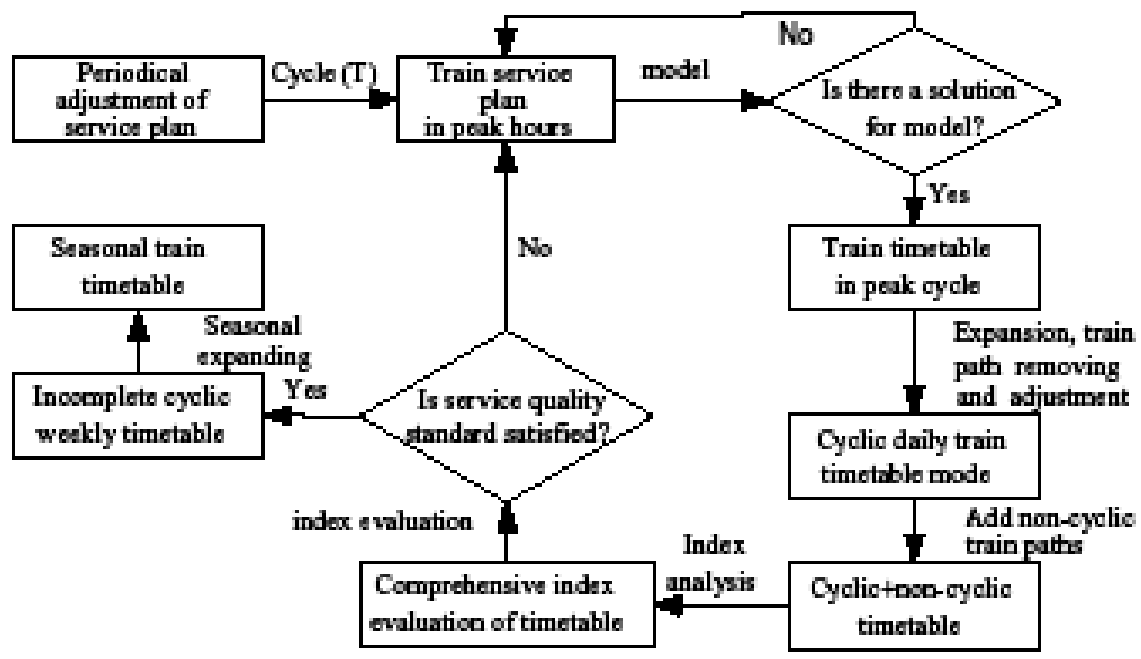

Figure 1: A flowchart of working out an incomplete cyclic timetable. 
Table 1: $\quad$ Statistics of China's opened high-speed railway lines.

\begin{tabular}{|c|c|c|c|}
\hline High-speed railway & $\begin{array}{c}\text { Length of } \\
\text { lines }(\mathrm{km})\end{array}$ & $\begin{array}{c}\text { Average number of } \\
\text { passengers } \\
\text { (ten thousand } \\
\text { per month) }\end{array}$ & $\begin{array}{c}\text { Average number of } \\
\text { passengers } \\
\text { (ten thousand } \\
\text { per day) }\end{array}$ \\
\hline Beijing-Tianjin & 137 & 162 & 5.4 \\
\hline $\begin{array}{c}\text { Shijiazhuang- } \\
\text { Taiyuan }\end{array}$ & 189 & 104 & 3.5 \\
\hline Coastal Railway & 557 & 123 & 4.1 \\
\hline Hefei-Wuhan & 356 & 50 & 1.7 \\
\hline Wuhan-Guangzhou & 1069 & 143 & 4.8 \\
\hline Zhengzhou-Xi'an & 484 & 23 & 0.8 \\
\hline
\end{tabular}

\subsubsection{Model development}

Some of China's HSR have long distance and heavy flow density. In order to control the problem scale and get a more practical solution, improvements can be made based on the existing model $[2,13]$.

When solving the model, the cyclic constrain variable $P$ can be defined as a 0 1 variable, as layover time can be reduced by improving station operation. If properly managed, the $P$ value is not equal $2 \mathrm{P}$ in all situations. In this way, the solution requiring scale can be further compressed and the solving difficulty can be lowered.

Moreover, some mathematical software can be used to solve model, such as CPLEX and LINGO.

\subsubsection{Non-cyclic train path insertion}

The non-cyclic train path inserting is a challenge of integrating timetable design and timetable adjustment. The necessary headway shall be guaranteed in inserting a train path for safety operation; moreover, the necessary linkage among trains for transfer shall also be considered. In addition, we shall try our best to keep the cyclic operation.

The solution for model is generally adopted to execute inserting. Based on considering influence on original cyclic graph and its own travel time, the objective of the model is:

$$
\min z=\alpha \cdot m+\beta \cdot n
$$

where $m$ is the influence of new-adding non-cyclic train paths on original timetable, so periodicity is the minimum; $n$ is the travel time of new-adding non-cyclic trains is the least; $\alpha$ is the weight of cyclic timetable influence factor; $\beta$ is weighing for travel time factor of inserted trains.

The following several aspects are mainly considered for constraint condition: constrain for arrival and departure time section; constraint for interval time of adjacent lines; constraint for dwell time; constraint for sectional running time. 


\subsubsection{Seasonal expansion}

The National Day, Spring Festival and summer holiday are peak period of passenger flow in China. The timetable can be properly adjusted to form particular seasonal timetable on the basis of prediction passenger flow fluctuation. In the seasonal timetable, cyclic trains are suitable for large passenger flow while non-cyclic trains are suitable for low frequency train. Hence, in the seasonal expansion course, the most important thing is to estimate which lines are suitable for cyclic lines to insert or for non-cyclic lines. The following two kinds of expansion modes shall be adopted flexibly with the fluctuation of passenger flow.

(1) Non-cyclic expansion: when the number of cycle affected by inserted non-cyclic train paths is small, the adjustment for the several cycles of inserted non-cyclic train paths can be executed. Moreover, the number of removing lines is determined on the basis of passenger flow.

(2) Cyclic expansion: when the number of cycle affected by inserted noncyclic train paths is large, the proper adjustment for each cycle can be executed in order to guarantee periodicity of timetable. In addition, removing paths is needed to meet the demand of passenger flow.

\section{Computer system for an incomplete cyclic timetable}

The above key issues show that incomplete cyclic timetable design is a very complicated task, so computer system is introduced to work out the timetable based on the key issues.

\subsection{System objective and framework}

The objective of system mainly include well embodiment of periodicity of timetable, friendly interface design, accurate data reading, favourable input and output functions, rapid information display, the human-computer interaction provided. However, how to solve the four key issues in the process of working out incomplete timetable is the most important thing for this computer system. So, some corresponding function should be designed to meet the demand of operator.

This system is developed on $\mathrm{VC}++$ platform and its framework mainly consists of three mutual nested classes including TimeTable, ParentTimeTableLine and SubTimeTableLine. The main functions of the three classes are introduced as follows: TimeTable is used for forming the base map of timetable and describing all of sectional stations and train running time of timetable; ParentTimeTableLine is used for describing some special train in timetable; and SubTimeTableLine is used for describing the running of all of the detailed trains in all of the sections.

\subsection{System functions}

This system designs four functional modules such as display, search, index statistics and human-computer interaction adjustment aiming for solving four key issues in incomplete cyclic timetable design, as is shown in Figure 2. 
Figure 2 shows that the system functions can not only work out a cyclic timetable quickly but also expand it to be an incomplete one easily. Obviously, four key issues have been solved in this system, and specific functions are described as below.

(1) Display function. The system accomplishes data input work through inputting the solution of model, and automatically forms timetable. So, the timetable can embody periodicity well.

(2) Search function. Three kinds of search functions are provided to supply convenience to users to obtain timetable relevant information. Search stations and time: click at any place in timetable and the time section and running section of this place can be obtained; Search train paths: show the relevant information of some certain train path; Search trains: input the serial number of trains through dialog box and the relevant information about this train can be displayed.

(3) Index statistics function. The system can form the relevant indexes of this timetable through calculation with respect to the formed timetable automatically, which supplies the feedback information. It's useful for the adjustment of timetable in anaphase.

(4) Human-computer interaction adjustment function. The functions of train path removing and train path inserting are designed in this system. Users can add, delete the non-cyclic train paths and modify the formed cyclic train paths as per passenger flow rule to adjust the cyclic timetable to 'cyclic + non-cyclic' mode timetable to supply convenience to users.

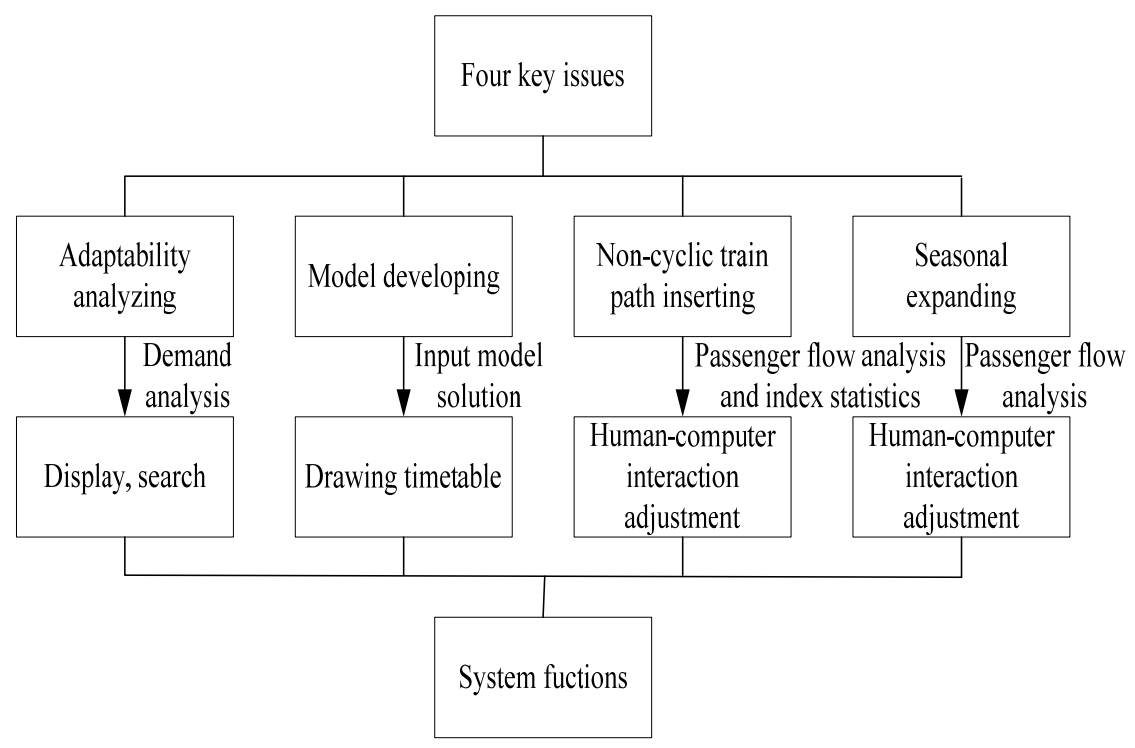

Figure 2: $\quad$ System function design. 


\section{The case study}

Beijing-Shanghai HSR being opened to traffic in 2012 will be the longest, fastest lines in china, and lots of scholars focus on the research of this line.

\subsection{Cyclic train service plan}

Referring to the preliminary service plan of Beijing-shanghai HSR designed by the 3rd China Railway Survey \& Design Institute, and in order to make the plan periodic, combination methods is adopted to complete the data processing. The final cyclic train service plan of Beijing-Shanghai HSR is shown in Figure 3.

The dwell plan will be formed by referring to the preliminary dwell plan designed by the 3rd Railway Survey \& Design Institute. The 21 stations can be classified into three grades. Trains of whose speed is less than $300 \mathrm{~km} / \mathrm{h}$ will stop at all of the stations. The final dwell plan is got through analyzing and amalgamating ODs based on passenger flow, as shown in Figure 4.

\subsection{Train departure and arrival order plan}

This paper uses improved fixed order model, the departure and arrival order of trains is required to be worked out.

Figure 5 shows the departure and arrival order of trains.

\subsection{Solution of the cyclic timetable model}

Figure 6 shows that the global optimal solution of model has been found.

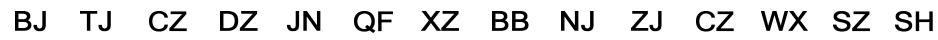

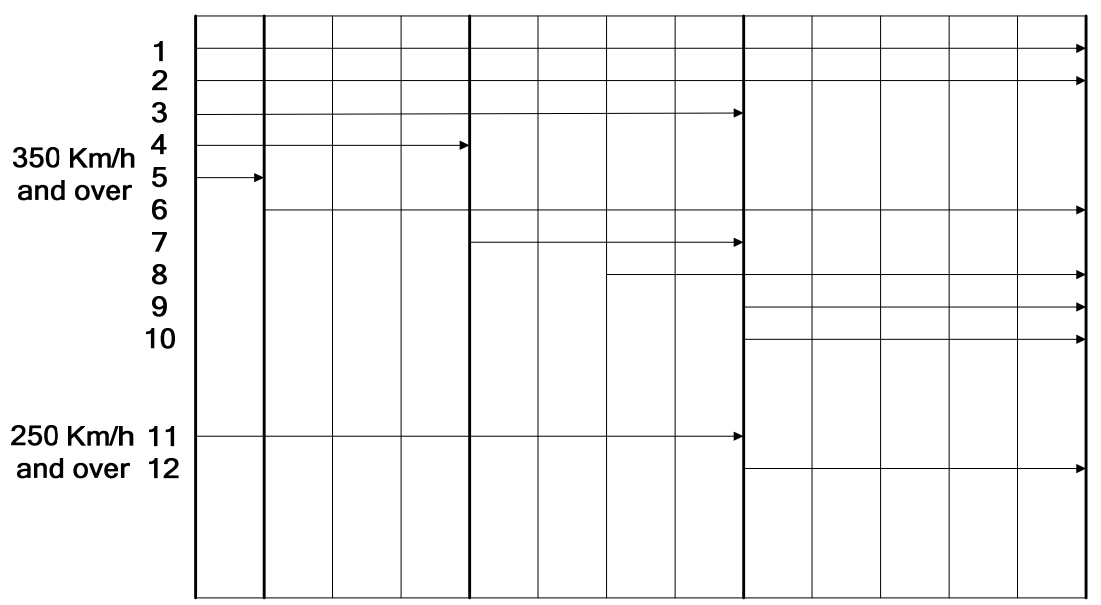

Figure 3: The cyclic train service plan of Beijing-Shanghai HSR. 


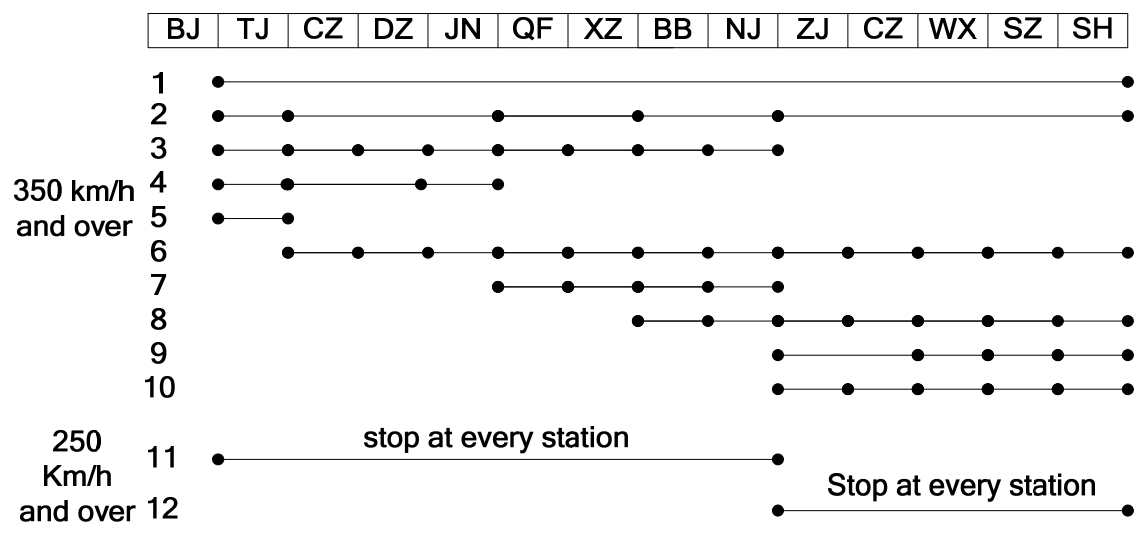

Figure 4: The dwell plan of Beijing-Shanghai HSR.

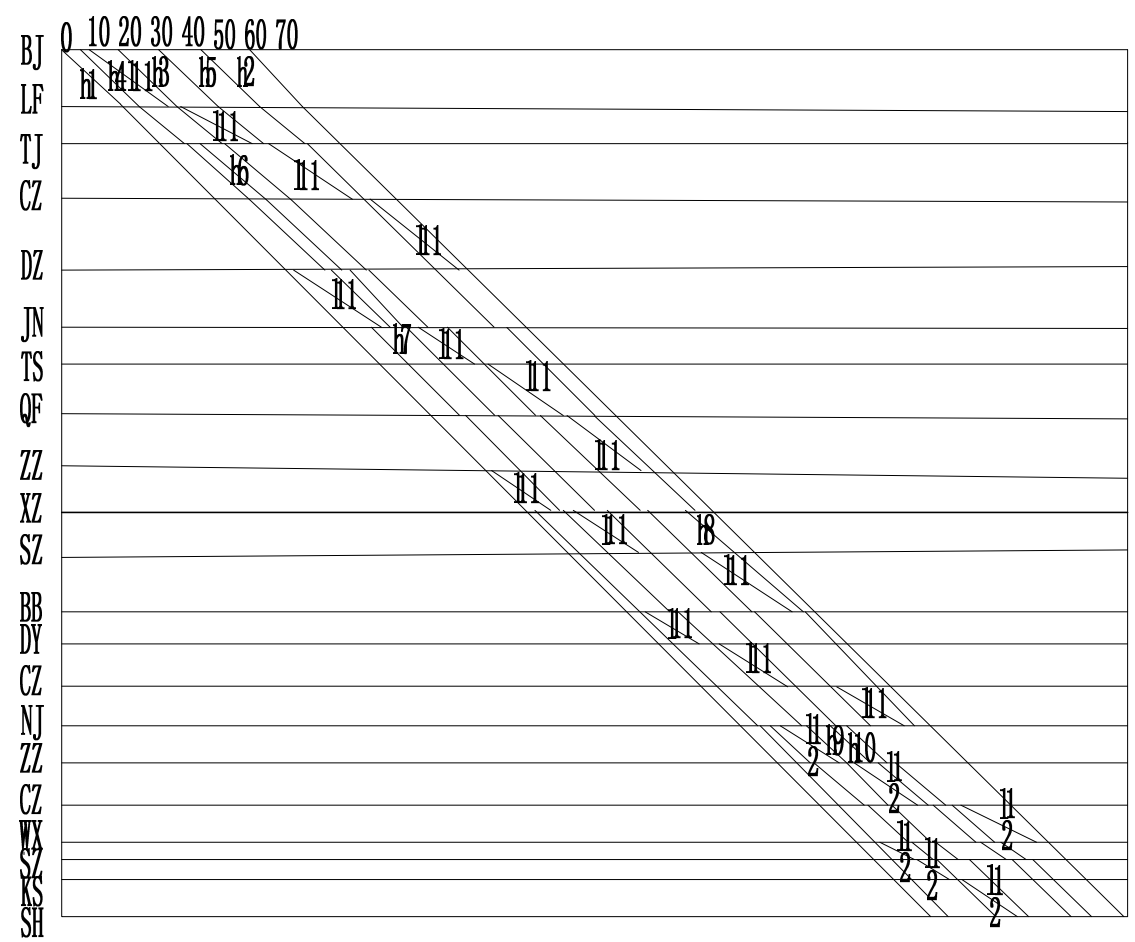

Figure 5: The departure and arrival order of trains on the Beijing-Shanghai HSR. 


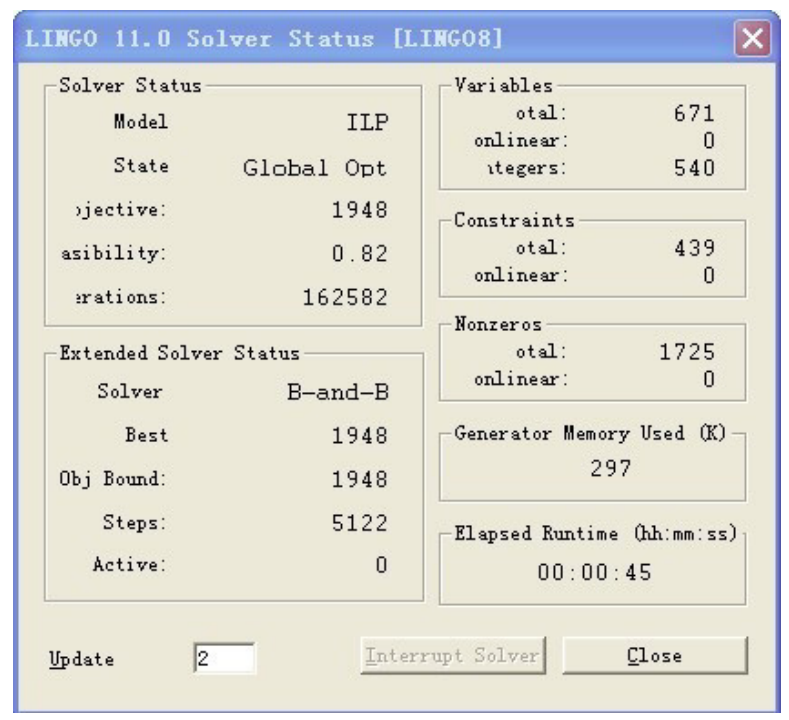

Figure 6: The LINGO solver status.

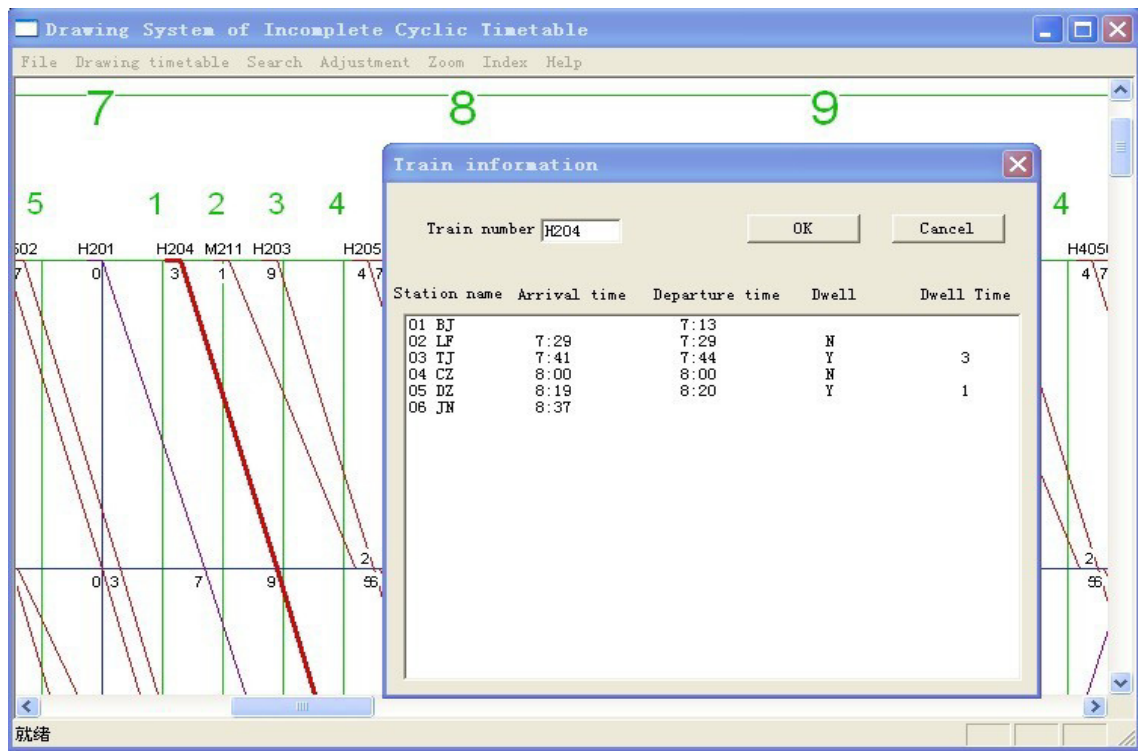

Figure 7: Train path search. 


\subsection{Timetable display}

The system reads the model solution and draws Beijing-shanghai HSR cyclic timetable, as is shown in Figure 7. Click any train path in the timetable and the corresponding train path will become bold line; click right key of the mouse and then, the relevant information of this path can be obtained

Moreover, in order to solve four issues, this system also has some functions such as human-computer interaction adjustment, zoom and index statistics. These functions will not be introduced detailed for its easy operation.

\section{Conclusion}

Developing cyclic timetable for HSR plays an important role in improving the operation efficiency and quality. In order to designing an economic, convenient, efficient and regular train timetable, the incomplete cyclic timetable mode which may be more suitable for china's HSR is presented in this paper. Through analyzing the work flow of this mode, four key issues in developing the timetable are discussed to provide the theoretical basis and technical support for the construction and operation of this important HSR. Simultaneously, computer system is suggested to develop for railway department to meet the demand of management.

Bases on the four key issues, this paper adopted the improved mathematical model and existing mathematical software to design and develop incomplete cyclic timetable mode computer system. The system solves four key issues in working out of incomplete cyclic timetable mode and realizes a series of practical functions such as model solution result input, timetable display, line information searching and human-computer interaction running adjustment. Through the case study of Beijing-Shanghai HSR, the system has been proved to be very practical and valuable.

Moreover, the solution of arrival and departure order of trains shall be worked out when utilizing fixed order model. How to sort out the feasible solution depends on many solutions of train arrival and departure order requires considering many factors. The solution adopted by this paper is manual working out. If the model can be applied for automatically creating train arrival and departure order, the efficiency will be largely improved. Further research is needed in order to create a model to work out the train departure and arrival order model which is meaningful for finding an optimization solution rapidly and improving efficiency.

\section{Acknowledgements}

This research was supported in part by the National Fund of Natural Science (60870012), the Ministry of Railway (2008X027-A, 2009BAG12A10 jointed support of the Ministry of Science and Technology) and the State Key Laboratory of Rail Traffic Control and Safety (RCS2009 ZT008). 


\section{References}

[1] Arjang Assad. Models for rail transportation [J]. Transportation Research, Vol.14, No.3, 1980.6

[2] Paolo Serafini, Walter Ukovich. A mathematical model for the fixed-time traffic control problem [J]. European Journal of Operational Research, 1989, 42(2): 152-165.

[3] Michiel A Odijk. A constraint generation algorithm for the construction of periodic railway timetables [J]. Transportation Research, 1996, 30(6): 455464.

[4] Carole Giesemann. Seminar on Algorithms and Models for Railway Optimization. University of Constance, 2002

[5] Karl Nachtigall, Stefan Voget. A genetic algorithm approach to periodic railway Synchronization [J]. Computers and Operations Research, Vol.23, No.5, 1996.5

[6] Thomas Lindner. Train schedule optimization in public rail transportation. Ph.D. thesis Technical University Braunschweig, Braunschweig, Germany, 2000

[7] Christian Liebchen, Leon Peeters. On Cyclic Timetabling and Cycles in Graphs. Technische Universitat Berlin, No. 761, 2002

[8] Paolo S, Walter U. A mathematical model for the fixed-time traffic control problem [J]. European Journal of Operational Research, 1989, 42 (2) : 152-165.

[9] Domschke, W. Schedule synchronization for public transit networks [J]. OR Spektrum, 1989, 11(1): 17-24.

[10] Shi Hao. Analysis on rational Applied Modes of High-Speed Train Diagram in Our Country [J]. Journal of the China Railway Society, 2000, 22(1): 92-97.

[11] Jia Yong-gang, Du Xu-sheng, Problems of Working out Train Timetable for Chinese Passenger Dedicated Line [J]. Railway Transportation and Economy, 2005, 28 (5) : 76-78.

[12] Wang Bo, Yang Hao, Zhang Zhi-hua. The Research on the Train Operation Plan of the Beijing-Tianjin Inter-city Railway Based on Periodic Train Diagrams [J]. Journal of the China Railway Society, 2007, 29: 8-13.

[13] Xie Mei-quan, Nie Lei. The Model of Working out Cyclic Train Timetable[J], Journal of the China Railway Society, 2009, 4: 7-13.

[14] Xie Mei-quan, Su Mei, Mao Bao-hua, Gao Li-ping, Liang Xiao. Problem of Cyclic Railway Timetable Based on High-Speed Network[C]. 2009 China control and decision-making conference papers (2), 2009.

[15] Chen Yong, Xie An-liang, Sun Quan-xin, Hu Si-ji. Research on Drawing System of Train Running Diagram of High Speed Railway [J]. Railway Computer Application. Vol.9, No.4, 2000:4-7. 